\title{
Optimisation of machining parameters on milling of GFRP composites by desirability function analysis using Taguchi method
}

\author{
M.P. Jenarthanan ${ }^{1}$, R. Jeyapaul ${ }^{2}$ \\ ${ }^{1 *}$ Department of Production Engineering, National Institute of Technology, Tiruchirappalli, INDIA \\ ${ }^{2}$ Department of Production Engineering, National Institute of Technology, Tiruchirappalli,, INDIA \\ *Corresponding Author: e-mail: jenavaish@gmail.com, Tel 09952552924.
}

\begin{abstract}
Milling of GFRP composite materials is a rather complex task owing to its heterogeneity and the number of problems, such as surface delamination, which appear during the machining process, associated with the characteristics of the material and the cutting parameters. Optimization of machining parameters is an important step in machining. This paper presents a new approach for optimizing the machining parameters on milling glass-fibre reinforced plastic (GFRP) composites. Optimization of machining parameters was done by an analysis called desirability function analysis (DFA), which is a useful tool for optimizing multi-response problems. In this work, based on Taguchi's $\mathrm{L}_{27}$ orthogonal array, milling experiments were conducted for GFRP composite plates using solid carbide end mills with different helix angles. The machining parameters such as, spindle speed, feed rate, helix angle and fibre orientation angle are optimized by multi-response considerations namely surface roughness, delamination factor and machining force. A composite desirability value is obtained for the multi-responses using individual desirability values from the desirability function analysis. Based on composite desirability value, the optimum levels of parameters have been identified, and significant contribution of parameters is determined by analysis of variance.
\end{abstract}

Keywords: GFRP composites; Taguchi; Desirability function analysis; ANOVA; Solid carbide end mill.

DOI: http://dx.doi.org/10.4314/ijest.v5i4.3

\section{Introduction}

Composites are one of the most widely used materials because of their adaptability to different situations and the relative ease of combination with other materials to serve specific purposes and exhibit desirable properties. Glass fibre reinforced plastics (GFRP) composite is considered to be an economic alternative to various heavy exotic materials. Glass-fibre-reinforced plastic (GFRP), an advanced polymeric matrix composite material, the use of GFRP composites in engineering applications such as automotive, aircraft and manufacture of space ships and sea vehicles industries have been increased considerably in recent years due to their light weight, high modulus, specific strength, superior corrosion resistance, high fracture toughness and resistance to chemical and microbiological attacks (Hull et al, 1996). GFRP composite materials are extremely abrasive when machined. Thus the selection of the cutting tool and the cutting parameters is very important in the machining process. Fibre-glass is simply a composite consisting of glass fibres, either continuous or discontinuous, contained within a polymer matrix. The machining of composite is different from the conventional machining of metal due to the composite's anisotropic and non-homogeneous nature (Ramkumar et al, 2004). Milling is one of the most important machining processes in manufacturing parts made out of FRPs. However, unlike the milling of metals which is characterized by high material removal rates, milling of FRPs is conducted at much lower scale. The reason for this is that FRP components are largely made near net shape and any subsequent milling is limited mainly to de-burring and trimming as well as to achieving contour shape accuracy (Jamal, 2009). Milling composite materials are significantly affected by the tendency of these materials to delaminate under the action of machining forces, cutting force, feed force and depth force respectively (Sreejith et al, 2000 \& Ferreira et al, 1999). 
The surface roughness and delamination is the characteristic that could influence the dimensional precision, the performance of mechanical pieces and production costs. For these reasons there has been research and development with the objective of optimising cutting conditions, to obtain a desired machinability (Ramulu et al, 1993 \& Erisken, 1999). The works of various authors, when reporting on milling composite materials, have shown that the surface quality (surface roughness), machining force and delamination factor is strongly dependent on cutting parameters, tool geometry and cutting forces (Koplev et al,1983, Kaneeda 1989, Puw et al, 1995, Santhanakrishnan et al, 1988 \& Ramulu et al, 1994).

A new machinability index was proposed by Davim and Mata for the turning of hand laid up GFRP materials using polycrystalline diamond (PCD) and cemented carbide (K15) cutting tools. The investigation reveals that the PCD tool performs well compared to cemented carbide (K15) tool in terms of surface roughness and specific cutting pressure. Fibre orientation is a key factor that determines the surface integrity of a machined surface and $90^{\circ}$ is a critical angle, beyond which a severe subsurface damage will occur. If the fibre orientation angle is greater than $90^{\circ}$, the three distinct deformation zones appear, namely chipping, pressing and bouncing (Wang et al, 2003). Palanikumar et al. (2006) have also attempted to assess the influence of machining parameters on surface roughness in machining GFRP composites, it concludes that the feed rate has more influence on surface roughness and it is followed by cutting speed (Praveen Raj et al., 2010) carried out a study of surface roughness, precision and delamination factor in use of Ti-Namite carbide K10 end mill, Solid carbide K10 end mill and Tipped Carbide K10 end mill on GFRP composite material. The investigation reveals that, Ti-Namite coated carbide end mill and tipped carbide end mill produces less damage on GFRP composite material than the solid carbide end mill i.e., the delamination factor is smaller.

Davim (2001) attempted to study the influence of cutting conditions on surface roughness during turning by design of experiments and regression analysis. (Davim et al., 2005) evaluated the cutting parameters (cutting velocity and feed rate) on the surface roughness, and damage in milling laminate plates of carbon fibre-reinforced plastics (CFRPs) by Taguchi method. (Julie et $a l, 2007)$ presented a study of the Taguchi design application to optimise surface quality in a CNC face milling operation.

Adeel et al. (2010) presented experimental study to optimise the cutting parameters when measuring workpiece surface temperature and surface roughness by Taguchi techniques. The results showed that the workpiece surface temperature can be sensed and used effectively as an indicator to control the cutting performance and improves the optimisation process. They reported that it is possible to increase machine utilization and decrease production cost in an automated manufacturing environment. Suleyman et al. (2011) reported in an analysis based on the response surface methodology, that the tool nose radius is the dominant factor on the surface roughness in turning of AISI steel. (Godfrey et al, 2006) developed a model for correlating the interactions of drilling control parameters and their effects on axial force and torque acting on the cutting tool during drilling by means of response surface methodology. They reported that the drill torque varies non-linearly versus the cutting parameters (speed, feed rate, and diameter).

Machining force also plays a key role in analyzing the machining process of FRPs. The value of machining force in the work piece is determined using the equation:

$$
F_{m}=\sqrt{F_{X}^{2}+F_{y}^{2}+F_{z}^{2}}
$$

where $F_{m}$ - Machining Force, $F_{x}$ - Feed force, $F_{y}$ - Cutting force and $F_{z}$ - Thrust force.

Generally, machining force increases with feed rate and decreases with cutting velocity. Evaluation of machining parameters of hand layup GFRP related to machining force was also carried out by Davim et al. (2004) on milling using cemented carbide (K10) end mill. Singh et al. (2006) made an attempt to correlate the drilling-induced damage with the drilling parameters of unidirectional GFRP composite laminates. Asif et al. (2010) investigated the relationships and parametric interactions between the three controllable variables (voltage, rotational speed of electrode and feed rate) on the material removal rate, electrode wear ratio and surface roughness in EDM (Electrical Discharge Machining) milling of stainless steel by RSM.

Almost all the attempts to study the machining characteristics and its optimisation are based on traditional approaches such as analysis of variance (ANOVA), regression analysis and by using other mathematical models. Therefore, this paper presents a new approach to optimise the machining characteristics of GFRP composite plates using desirability function analysis (DFA). DFA is one of the most widely used methods in industry for the optimisation of multi-response characteristics. Desirability function analysis is used to convert the multi-response characteristics into single-response characteristics. As a result, optimisation of the complicated multi-response characteristics can be converted into optimisation of a single response characteristic termed composite desirability. It does not involve complicated mathematical theory or computation like in traditional approaches and thus can be employed by the engineers without a strong statistical background. The multi-responses such as surface roughness, delamination factor and machining force are combined as composite desirability using desirability function analysis.

\section{Experimental details}

\subsection{Material and tool}

Glass fibre reinforced plastics (GFRP) composite plates made by Hand lay-up method are used for these experiments. GFRP plates are of $150 \mathrm{~mm} \times 100 \mathrm{~mm} \times 3 \mathrm{~mm}$ thick with 12 lay-up with desired fibre orientation $\left(15^{\circ}, 60^{\circ}\right.$ and $\left.105^{\circ}\right)$ are used for the 
milling operations. The cutting tool is made up of solid carbide tool of $5 \mathrm{~mm}$ diameter. The solid carbide end mill of different helix angles $\left(25^{\circ}, 35^{\circ}\right.$, and $\left.45^{\circ}\right)$ are shown in Fig. 1 .

The fibre orientations are defined in clockwise with reference to the cutting direction as shown in Fig. 2. The experiments are conducted based on Taguchi $\mathrm{L}_{27}$ orthogonal array using a CNC milling machine. The CNC milling machine is an automated machinery, and its specifications are given in Table 1. The fixation of the composite material in the machining centre is as shown in Fig. 3 to make sure that vibrations and displacement are eliminated.

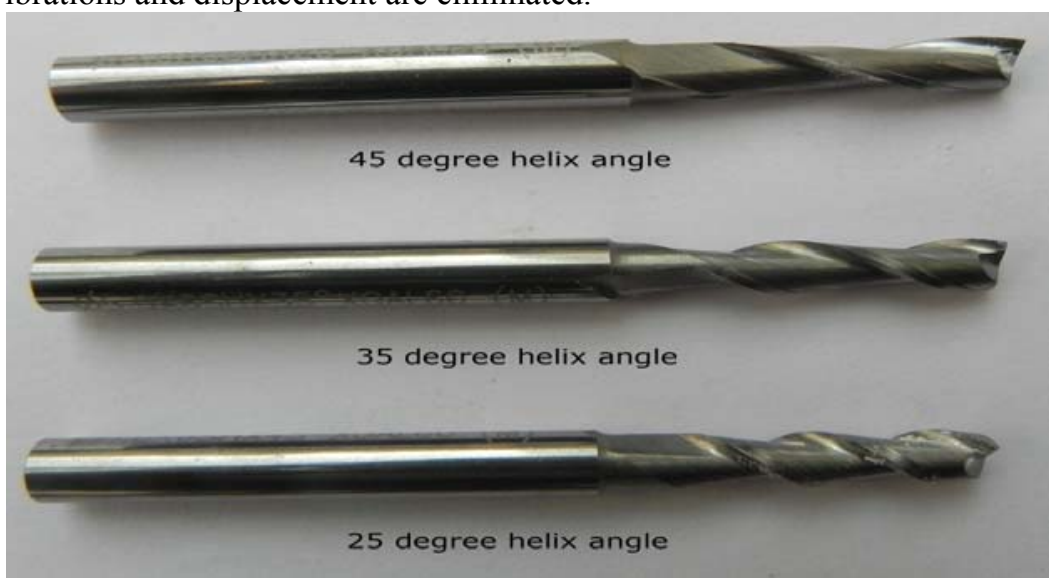

Fig. 1 Solid carbide end mill with different helix angles

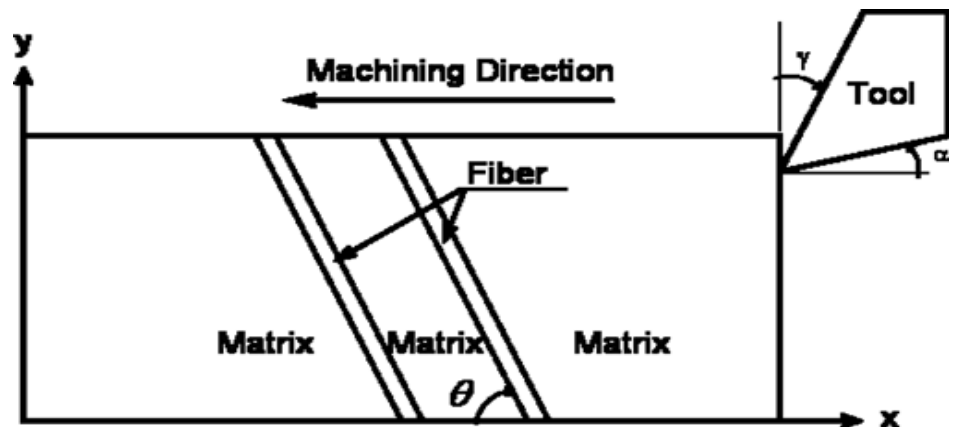

Fig. 2 Notation of the fibre orientation with respect to cutting tool movement.

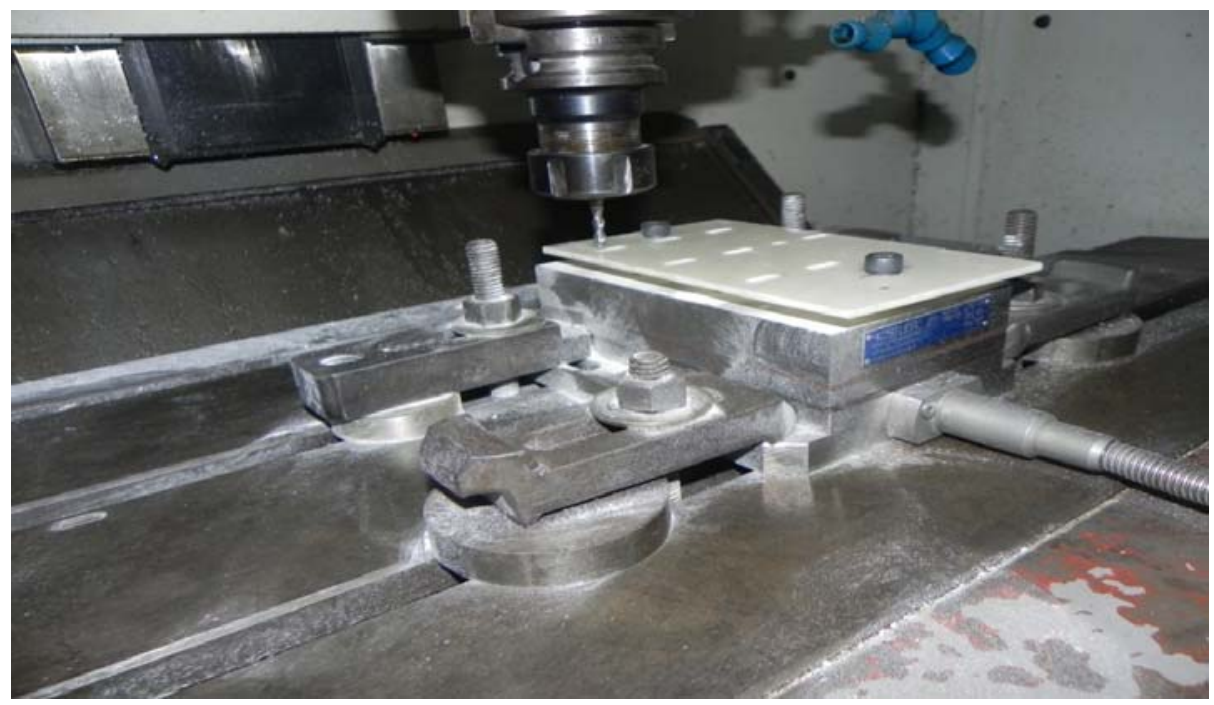

Fig. 3 Fixation of GFRP composite plate by using clamps in the machining centre. 
Table 1 Specification of the CNC milling machine

\begin{tabular}{ll}
\hline Type of machine & Vertical machine centre \\
Make & Hartford, Taiwan \\
Table size & $810 \times 400 \mathrm{~mm}$ \\
Spindle motor power & $7.5 \mathrm{KW}$ \\
Spindle speed & $60-8000 \mathrm{rpm}$ \\
Feed & $1-7000 \mathrm{~mm} / \mathrm{min}$ \\
X axis & $510 \mathrm{~mm}$ \\
Y axis & $400 \mathrm{~mm}$ \\
Z axis & $400 \mathrm{~mm}$ \\
Accuracy (Positioning) & $\pm 0.005 / 300 \mathrm{~mm}$ \\
\hline
\end{tabular}

\subsection{Process parameters}

The independently controllable predominant machining parameters that are having greater influences on the surface finish of GFRP composite work piece have been identified. They are:

(i) Work piece fibre orientation angle,

(ii) Helix angle,

(iii) Feed rate, and

(iv) Spindle speed

A detailed analysis has been carried out to fix the lower and upper limits of the factors. Based on the analysis, the upper and lower limits of the factors are identified and are given below. Previous studies mentioned in the literature indicated that, the surface roughness increases with increase of spindle speed. But very high spindle speed was found to cause a large deformation rate of glass fibre and it produces imperfection in surface and hence the spindle speed has been fixed between 2000 and 6000 $\mathrm{rev} / \mathrm{min}$. The fibre orientation angle plays an important role for deciding the surface roughness. The previous results indicated that fibre orientation angle is one of the important aspects, which affect the surface roughness. For the present study, the fibre orientation angle considered is between $15^{\circ}$ and $105^{\circ}$. Feed rate is the main parameter, which affect the machining process. The increase in feed rate increases the chatter and it produces incomplete machining at a faster traverse, which led to higher surface roughness and hence low limit of feed rates are advisable in machining GFRP composites. In the present study, the feed rate is selected between 0.04 and $0.12 \mathrm{~mm} / \mathrm{rev}$. The helix angle also an another important parameters which affects on machining force and surface roughness and hence three different helix angles $\left(25^{\circ}, 35^{\circ}\right.$, and $\left.45^{\circ}\right)$ are chosen in this study. The identified parameters and their levels chosen are summarized in Table 2.

Table 2 Process control parameters and their levels

\begin{tabular}{|l|c|c|c|c|c|}
\hline & & & \multicolumn{3}{|c|}{ Levels } \\
\hline Process parameters & Units & Notation & 1 & 2 & 3 \\
\hline Fibre orientation angle & ${ }^{\circ}$ (degrees) & $\Phi$ & 15 & 60 & 105 \\
Helix angle & ${ }^{\circ}$ (degrees) & $\Theta$ & 25 & 35 & 45 \\
Spindle speed & $\mathrm{rpm}$ & $\mathrm{N}$ & 2000 & 4000 & 6000 \\
Feed rate & $\mathrm{mm} / \mathrm{rev}$ & $\mathrm{F}$ & 0.04 & 0.08 & 0.12 \\
\hline
\end{tabular}

\subsection{Measurements}

The Output responses considered in this study are surface roughness $\left(\mathrm{R}_{\mathrm{a}}\right)$, delamination factor $\left(\mathrm{F}_{\mathrm{d}}\right)$ and machining force $\left(\mathrm{F}_{\mathrm{m}}\right)$. The measurement and calculation of responses based on the input parameters are described below.

\subsubsection{Measurement of Surface Roughness}

The surface roughness value of the machined surfaces is measured in order to analyze the surface finish quality. The surface roughness of a machined product could affect contact causing surface friction, wearing, light reflection, heat transmission, the ability for distributing and holding a lubricant, coating, and resisting fatigue. The surface roughness $\left(\mathrm{R}_{\mathrm{a}}\right)$ was evaluated using stylus type profilometer Mitutoyo SJ-201. For each test, five measurements were made over milling surfaces, according to Fig. 4. Considering the number of measurements to be carried out, a programmable technique was used, by previously selecting a roughness profile, the cut-off $(0.8 \mathrm{~mm})$ and the roughness evaluator parameter $\left(\mathrm{R}_{\mathrm{a}}\right)$ according to ISO. 


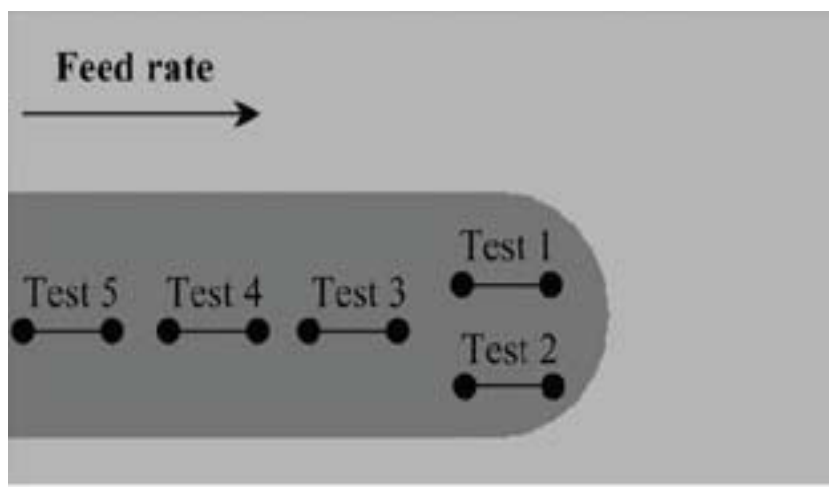

Fig. 4 Diagram of measurement that were made over each milling surface

\subsubsection{Measurement of Delamination Factor}

The damage caused on the GFRP composite material was measured perpendicular to the feed rate with a shop microscope Mitutoyo TM-500, as observed in Fig. 5. The composite material was positioned and fixed on the $X Y$ stage glass of the microscope, and then the alignment of an initial measuring point with one of the cross-hairs was made on the machined feature. Moving the $X Y$ stage glass by turning the micrometer head with a Digital Counter to the final point with the same cross-hair has been measured the damage (maximum width). After the measurement of the maximum width of damage $\left(W_{\max }\right)$ suffered by the material, the damage normally assigned by delamination factor $\left(F_{d}\right)$ was determined. This factor is defined as the quotient between the maximum width of damage $\left(W_{\max }\right)$, and the width of cut $(W)$. The value of delamination factor $\left(F_{d}\right)$ can be obtained by the following equation:

$$
F_{d}=\frac{W_{\max }}{W}
$$

Where $\mathrm{W}_{\max }$ being the maximum width of damage in $\mathrm{mm}$ and $\mathrm{W}$ be the width of cut in $\mathrm{mm}$

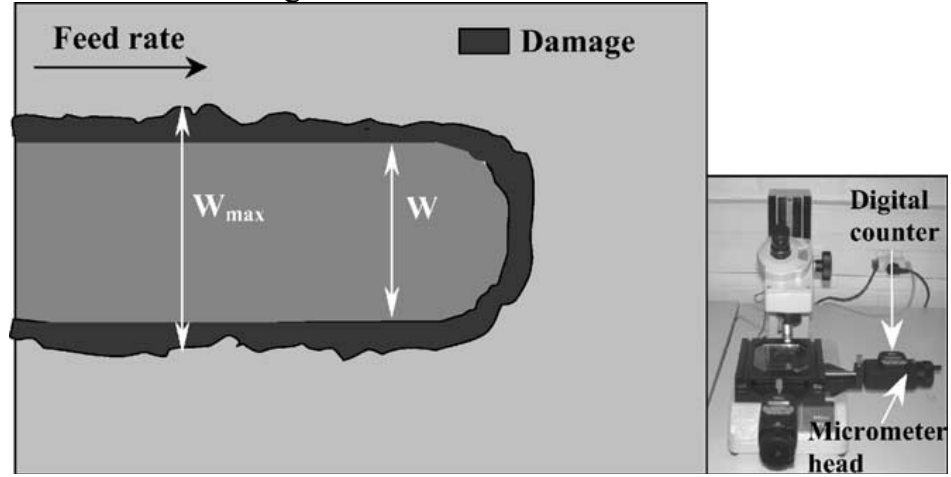

Fig. 5 Diagram of the measurement of the width of maximum damage with a shop microscope Mitutoyo TM 500

\subsubsection{Machining force}

Force measurement in manufacturing, especially in machining, is very important. This is because:

- Force measurement can be used for monitoring the tool conditions, and avoiding breakage during the machining process.

- Force measurement helps us understand machining process, because cutting force is one of the most sensitive indicators of machining performance. Both the static and dynamic components of the cutting force contain information concerning the state of chip formation and the cutting tool.

- Force measurement enables engineer to optimize manufacturing process and design proper machining tool.

The force measurement was carried out using a Kistler dynamometer. The data acquisition was carried out by appropriate software called Dynawarekistler. The value of machining force in the work piece is determined using the Eq. 2 .

$$
F_{m}=\sqrt{F_{x}^{2}+F_{y}^{2}+F_{z}^{2}}
$$




\section{Methodology}

\subsection{Plan of Experiments}

Robust design is an engineering methodology for obtaining product and process conditions which are minimally sensitive to the various causes of variation to produce high-quality products with low development and manufacturing costs. Taguchi's parameter design is an important tool for robust design. It offers a simple and systematic approach to optimize design for performance, quality and cost. Taguchi methods which combine the experiment design theory and the quality loss function are applied to the robust design of products and process. Taguchi method uses a special design of orthogonal arrays to study the entire parameter space with a small number of experiments. The methodology of Taguchi for four factors at three levels is used for the experiments. The factors and levels assumed are tabulated in Table 2. The orthogonal array $\mathrm{L}_{27}$ is selected as shown in Table 3 , which has 27 rows corresponding to the number of tests with the required columns. The plan of experiments comprises 27 tests where the second column is assigned to the fibre orientation angle $(\Phi)$, the third column is assigned to the helix angle $(\Theta)$, the fourth column is assigned to the spindle speed $(\mathrm{N})$ and the fifth is to the feed rate (f). The quality characteristics are surface roughness, delamination factor and machining force.

3.2 Desirability Function Analysis (DFA)

DFA is one of the most widely used methods in industry for the optimization of multi-response characteristics. Desirability function analysis is used to convert the multi-response characteristics into single-response characteristics. As a result, optimization of the complicated multi-response characteristics can be converted into optimization of a single response characteristic termed composite desirability. The multi-responses such as surface roughness, delamination factor and machining force are combined as composite desirability using desirability function analysis.

3.2.1 Optimisation steps using desirability function analysis in the Taguchi method

Step 1: Calculate the individual desirability index $\left(\mathrm{d}_{\mathrm{i}}\right)$ for the corresponding responses using the formula proposed by the Derringer and Suich [28]. There are three forms of the desirability functions according to the response characteristics.

The-nominal-the best: The value of $\hat{y}$ is required to achieve a particular target $\mathrm{T}$. When the $\hat{y}$ equals to $\mathrm{T}$, the desirability value equals to 1 ; if the departure of $\hat{y}$ exceeds a particular range from the target, the desirability value equals to 0 , and such situation represents the worst case. The desirability function of the nominal-the-best can be written as given in Eq. 3:

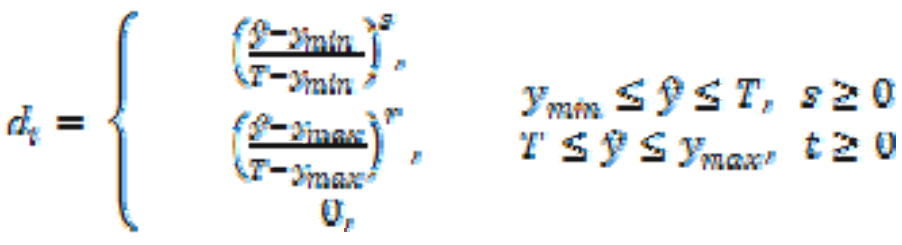

Where the $\mathrm{y}_{\max }$ and $\mathrm{y}_{\min }$ represent the upper/lower tolerance limits of $\hat{y}$ and $\mathrm{s}$ and $\mathrm{t}$ represent the weights.

The-larger-the better: The value of $y$ is expected to be the larger the better. When the $y$ exceeds a particular criteria value, which can be viewed as the requirement, the desirability value equals to 1 ; if the $\hat{y}$ is less than a particular criteria value, which is unacceptable, the desirability value equals to 0 . The desirability function of the larger- the better can be written as given in Eq. 4 :

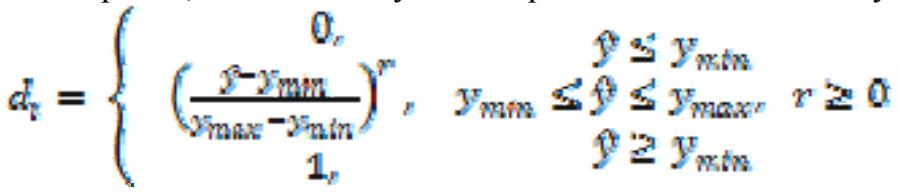

The-smaller-the better: The value of $\hat{y}$ is expected to be the smaller the better. When the $\hat{y}$ is less than a particular criteria value, the desirability value equals to 1 ; if the $\hat{y}$ exceeds a particular criteria value, the desirability value equals to 0 . The desirabilityfunction of the-smaller-the-better can be written as given in Eq. 5:

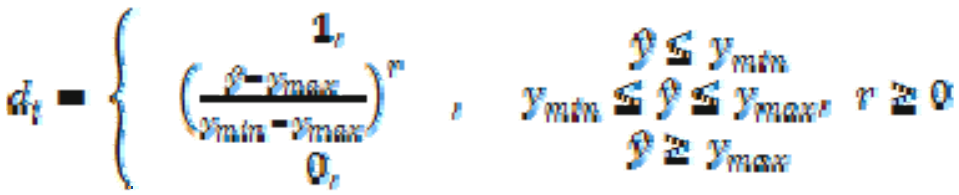

where the $\mathrm{y}_{\min }$ represents the lower tolerance limit of $\hat{y}$, the $\mathrm{y}_{\max }$ represents the upper tolerance limit of $\hat{y}$ and $\mathrm{r}$ represents the weight. The $\mathrm{s}, \mathrm{t}$ and $\mathrm{r}$ in Eqs.3, 4 and 5indicate the weights and are defined according to the requirement of the user. If the corresponding response is expected to be closer to the target, the weight can be set to the larger value; otherwise, the weight can be set to the smaller value. 
In this study, "the smaller the better" characteristic is applied to determine the individual desirability values for surface roughness, delaminaion factor and machining force since all responses are to be minimized.

Step 2: Compute the composite desirability $\left(\mathrm{d}_{\mathrm{G}}\right)$. The individual desirability index of all the responses can be combined to form a single value called composite desirability $\left(\mathrm{d}_{\mathrm{G}}\right)$ by the following Eq. 6 :

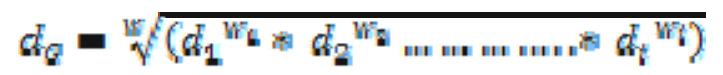

where $d_{i}$ is the individual desirability of the property $Y_{i}, w_{i}$ is the weight of the property " $Y_{i}$ " in the composite desirability and $w$ is the sum of the individual weights.

Step 3: Determine the optimal parameter and its level combination. The higher composite desirability value implies better product quality. Therefore, on the basis of the composite desirability $\left(\mathrm{d}_{\mathrm{G}}\right)$, the parameter effect and the optimum level for each controllable parameter are estimated.

Step 4: Perform ANOVA for identifying the significant parameters. ANOVA establishes the relative significance of parameters. The calculated total sum of square values is used to measure the relative influence of the parameters.

\section{Results and Discussion}

The machinability in this work was evaluated by surface roughness $\left(R_{a}\right)$ of the machined surface of the work piece, machining force and delamination factor. The results obtained through experiments are presented in Table 3. The Taguchi's approach to experimental design is described below. The first step in the Taguchi method is to determine the quality characteristic which is to be optimized.

\begin{tabular}{|c|c|c|c|c|c|c|c|}
\hline $\mathrm{TCN}$ & $\begin{array}{c}\text { Fibre } \\
\text { orientation } \\
\text { angle }\left(^{\circ}\right)\end{array}$ & $\begin{array}{l}\text { Helix } \\
\text { angle } \\
\left({ }^{\circ}\right)\end{array}$ & $\begin{array}{l}\text { Spindle } \\
\text { speed } \\
(\mathrm{rpm})\end{array}$ & $\begin{array}{l}\text { Feed rate } \\
(\mathrm{mm} / \mathrm{min})\end{array}$ & $\begin{array}{c}\text { Surface } \\
\text { roughness } \\
(\mu \mathrm{m})\end{array}$ & $\begin{array}{l}\text { Machining } \\
\text { force }(\mathrm{N})\end{array}$ & $\begin{array}{l}\text { Delamin- } \\
\text { ation factor }\end{array}$ \\
\hline 1 & 15 & 25 & 2000 & 0.04 & 0.91 & 15.27 & 1.009 \\
\hline 2 & 15 & 25 & 4000 & 0.08 & 0.85 & 20.78 & 1.015 \\
\hline 3 & 15 & 25 & 6000 & 0.12 & 0.95 & 22.79 & 1.019 \\
\hline 4 & 15 & 35 & 2000 & 0.08 & 1.10 & 19.25 & 1.025 \\
\hline 5 & 15 & 35 & 4000 & 0.12 & 1.18 & 21.64 & 1.012 \\
\hline 6 & 15 & 35 & 6000 & 0.04 & 0.92 & 14.21 & 1.021 \\
\hline 7 & 15 & 45 & 2000 & 0.12 & 1.59 & 20.79 & 1.032 \\
\hline 8 & 15 & 45 & 4000 & 0.04 & 1.32 & 13.54 & 1.024 \\
\hline 9 & 15 & 45 & 6000 & 0.08 & 1.30 & 18.15 & 1.017 \\
\hline 10 & 60 & 25 & 2000 & 0.04 & 1.08 & 26.24 & 1.011 \\
\hline 11 & 60 & 25 & 4000 & 0.08 & 1.25 & 28.16 & 1.021 \\
\hline 12 & 60 & 25 & 6000 & 0.12 & 1.29 & 30.14 & 1.034 \\
\hline 13 & 60 & 35 & 2000 & 0.08 & 1.62 & 24.32 & 1.040 \\
\hline 14 & 60 & 35 & 4000 & 0.12 & 1.69 & 31.84 & 1.057 \\
\hline 15 & 60 & 35 & 6000 & 0.04 & 1.48 & 21.19 & 1.031 \\
\hline 16 & 60 & 45 & 2000 & 0.12 & 1.82 & 32.15 & 1.067 \\
\hline 17 & 60 & 45 & 4000 & 0.04 & 1.58 & 20.79 & 1.058 \\
\hline 18 & 60 & 45 & 6000 & 0.08 & 1.62 & 25.62 & 1.061 \\
\hline 19 & 105 & 25 & 2000 & 0.04 & 1.39 & 39.24 & 1.038 \\
\hline 20 & 105 & 25 & 4000 & 0.08 & 1.64 & 37.25 & 1.047 \\
\hline 21 & 105 & 25 & 6000 & 0.12 & 1.72 & 59.61 & 1.075 \\
\hline 22 & 105 & 35 & 2000 & 0.08 & 1.98 & 39.25 & 1.059 \\
\hline 23 & 105 & 35 & 4000 & 0.12 & 2.08 & 41.52 & 1.079 \\
\hline 24 & 105 & 35 & 6000 & 0.04 & 1.68 & 29.72 & 1.032 \\
\hline 25 & 105 & 45 & 2000 & 0.12 & 2.48 & 38.62 & 1.092 \\
\hline 26 & 105 & 45 & 4000 & 0.04 & 2.06 & 29.15 & 1.047 \\
\hline 27 & 105 & 45 & 6000 & 0.08 & 2.12 & 19.26 & 1.057 \\
\hline
\end{tabular}

The output or response variable which influences effectively on the quality of product is known as quality characteristic. In this study, the surface roughness, machining force and delamination factor are the quality characteristics. In the second step, the control parameters or test parameters which have significant effects on the quality characteristic are identified with the required number of levels. In the third step, the appropriate orthogonal array for the control parameters is selected after calculating the minimum 
number of experiments required to be conducted by considering the interactive effects. The experimental test conditions and observed data are shown in Table. 3. In order to get good surface quality and dimensional properties, it is necessary to employ optimization techniques to find optimal process parameters. Taguchi and desirability function analysis can be conveniently used for these purposes, and hence, the aforementioned methodologies are opted to optimize the machining parameters in this work.

\subsection{Results of individual and composite desirability}

Optimal combinations of parameters are determined based on assumed weightage of 2:3:5 for delamination factor, machining force and surface roughness, respectively. The weightage of parameters was assumed on the basis of physical significance of each parameter during machining. Surface roughness plays an important role in many areas and is a factor of greater importance in the evaluation of machining accuracy, and hence, it is given maximum weightage. Machining force plays the next prominent role after surface roughness, and therefore, the next best weightage was assumed to it. Apart from surface roughness and machining force, delamination also contributes significantly in determining the optimum machining characteristics. Hence, the weightage for delamination factor was assumed to be the least. The individual desirability values for, surface roughness, machining force and delamination factor are calculated and presented in Table 4. Based on assumed weightage, the composite desirability values are also calculated and tabulated in Table 4.

Table 4 Individual desirability and composite desirability

\begin{tabular}{|c|c|c|c|c|c|c|c|c|}
\hline \multirow{2}{*}{ TCN } & \multirow{2}{*}{$\begin{array}{c}\text { Fibre } \\
\text { orientation } \\
\text { angle }\left({ }^{\circ}\right)\end{array}$} & \multirow{2}{*}{$\begin{array}{l}\text { Helix } \\
\text { angle } \\
\left(^{\circ}\right)\end{array}$} & \multirow{2}{*}{$\begin{array}{l}\text { Spindle } \\
\text { speed } \\
\text { (rpm) }\end{array}$} & \multirow{2}{*}{$\begin{array}{l}\text { Feed rate } \\
(\mathrm{mm} / \mathrm{min})\end{array}$} & \multicolumn{3}{|c|}{ Individual desirability $\left(\mathrm{d}_{\mathrm{i}}\right)$} & \multirow{2}{*}{$\begin{array}{l}\text { Composite } \\
\text { desirability } \\
\left(\mathrm{d}_{\mathrm{G}}\right)\end{array}$} \\
\hline & & & & & $\mathrm{R}_{\mathrm{a}}$ & $\mathrm{F}_{\mathrm{m}}$ & $\mathrm{Fd}$ & \\
\hline 1 & 15 & 25 & 2000 & 0.04 & 0.963 & 0.962 & 1.000 & 0.970 \\
\hline 2 & 15 & 25 & 4000 & 0.08 & 1.000 & 0.843 & 0.928 & 0.936 \\
\hline 3 & 15 & 25 & 6000 & 0.12 & 0.938 & 0.799 & 0.879 & 0.883 \\
\hline 4 & 15 & 35 & 2000 & 0.08 & 0.846 & 0.876 & 0.807 & 0.847 \\
\hline 5 & 15 & 35 & 4000 & 0.12 & 0.797 & 0.824 & 0.964 & 0.836 \\
\hline 6 & 15 & 35 & 6000 & 0.04 & 0.957 & 0.985 & 0.855 & 0.944 \\
\hline 7 & 15 & 45 & 2000 & 0.12 & 0.546 & 0.843 & 0.723 & 0.658 \\
\hline 8 & 15 & 45 & 4000 & 0.04 & 0.712 & 1.000 & 0.819 & 0.811 \\
\hline 9 & 15 & 45 & 6000 & 0.08 & 0.724 & 0.899 & 0.904 & 0.808 \\
\hline 10 & 60 & 25 & 2000 & 0.04 & 0.859 & 0.724 & 0.976 & 0.837 \\
\hline 11 & 60 & 25 & 4000 & 0.08 & 0.755 & 0.682 & 0.855 & 0.751 \\
\hline 12 & 60 & 25 & 6000 & 0.12 & 0.730 & 0.639 & 0.699 & 0.695 \\
\hline 13 & 60 & 35 & 2000 & 0.08 & 0.528 & 0.766 & 0.626 & 0.610 \\
\hline 14 & 60 & 35 & 4000 & 0.12 & 0.485 & 0.603 & 0.422 & 0.503 \\
\hline 15 & 60 & 35 & 6000 & 0.04 & 0.613 & 0.834 & 0.735 & 0.697 \\
\hline 16 & 60 & 45 & 2000 & 0.12 & 0.405 & 0.596 & 0.301 & 0.428 \\
\hline 17 & 60 & 45 & 4000 & 0.04 & 0.552 & 0.842 & 0.409 & 0.590 \\
\hline 18 & 60 & 45 & 6000 & 0.08 & 0.528 & 0.738 & 0.373 & 0.544 \\
\hline 19 & 105 & 25 & 2000 & 0.04 & 0.668 & 0.442 & 0.650 & 0.587 \\
\hline 20 & 105 & 25 & 4000 & 0.08 & 0.515 & 0.485 & 0.542 & 0.511 \\
\hline 21 & 105 & 25 & 6000 & 0.12 & 0.466 & 0.000 & 0.205 & 0.000 \\
\hline 22 & 105 & 35 & 2000 & 0.08 & 0.307 & 0.442 & 0.397 & 0.360 \\
\hline 23 & 105 & 35 & 4000 & 0.12 & 0.245 & 0.393 & 0.157 & 0.258 \\
\hline 24 & 105 & 35 & 6000 & 0.04 & 0.491 & 0.649 & 0.723 & 0.576 \\
\hline 25 & 105 & 45 & 2000 & 0.12 & 0.000 & 0.455 & 0.000 & 0.000 \\
\hline 26 & 105 & 45 & 4000 & 0.04 & 0.258 & 0.661 & 0.542 & 0.397 \\
\hline 27 & 105 & 45 & 6000 & 0.08 & 0.221 & 0.876 & 0.422 & 0.380 \\
\hline
\end{tabular}

\subsection{Effect of process parameters on responses}

The influence of process parameters on surface roughness, machining force and delamination factor are shown in Fig. 6- 8. 


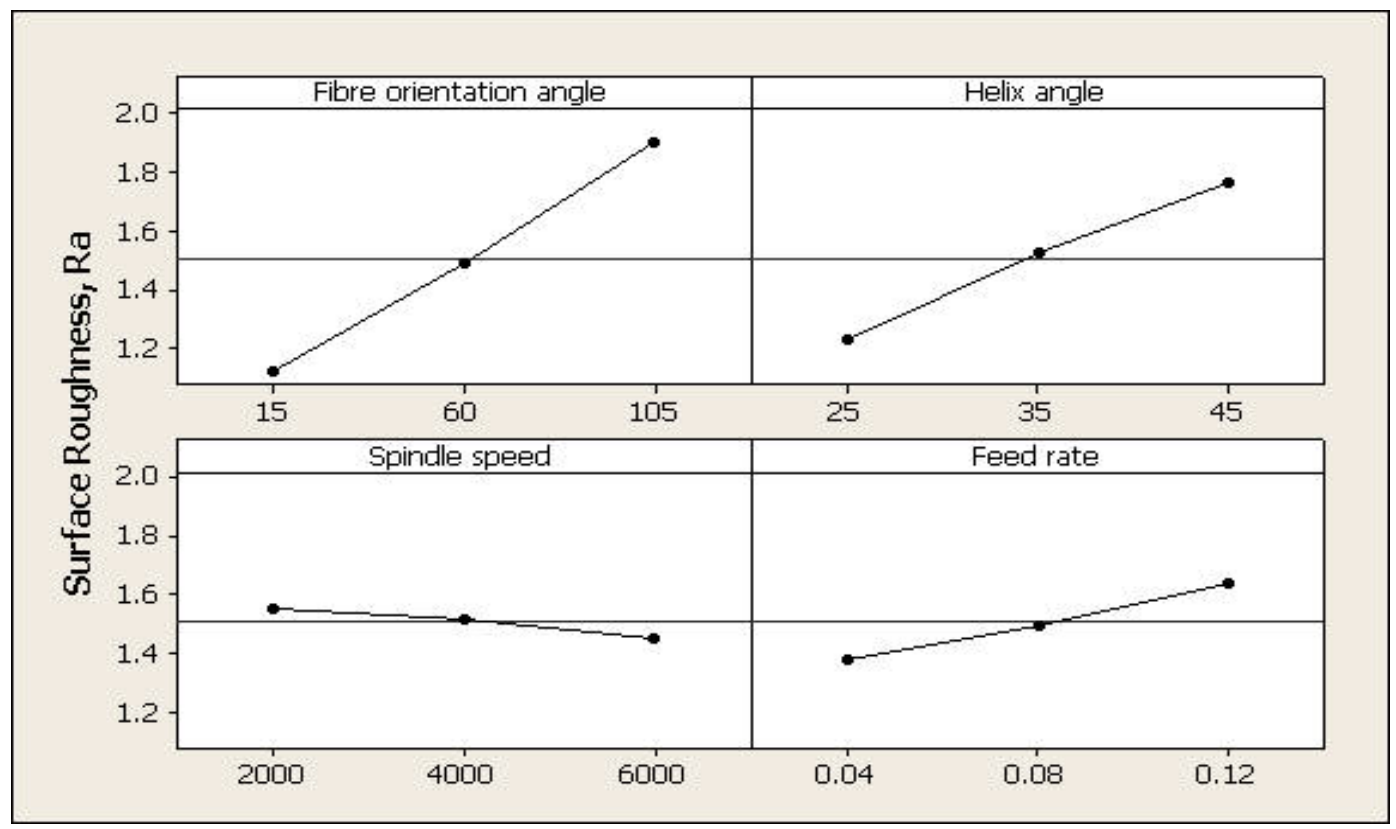

Fig. 6 Effect of process parameters on surface roughness

The effect of fibre orientation angle, feed rate, helix angle and spindle speed on surface roughness is shown in Fig. 6. As it is seen from figure, the surface roughness tends to increase steadily with an increase in fibre orientation angle, helix angle and feed rate, and decreases considerably with an increase of spindle speed. This is due to an increase in the feed per tooth (resulting from increasing the feed rate), which causes a significant rise in surface roughness. Fig. 7 shows the effect of fibre orientation angle, feed rate, helix angle and spindle speed on machining force. As it is seen from figure, the machining force tends to increase steadily with an increase in fibre orientation angle and feed rate, and decreases considerably with an increase in helix angle and spindle speed. End mills with small helix angles develop the greatest machining force. The effect of fibre orientation angle, feed rate, helix angle and spindle speed on delamination factor is shown in fig.8. As it is seen from figure, the delamination factor tends to increase steadily with an increase in fibre orientation angle, helix angle and feed rate, and decreases considerably with an increase of spindle speed. This is due to the increase in the feed rate causes a sharp rise in the feed force which causes higher friction and produces more damage on the surface.

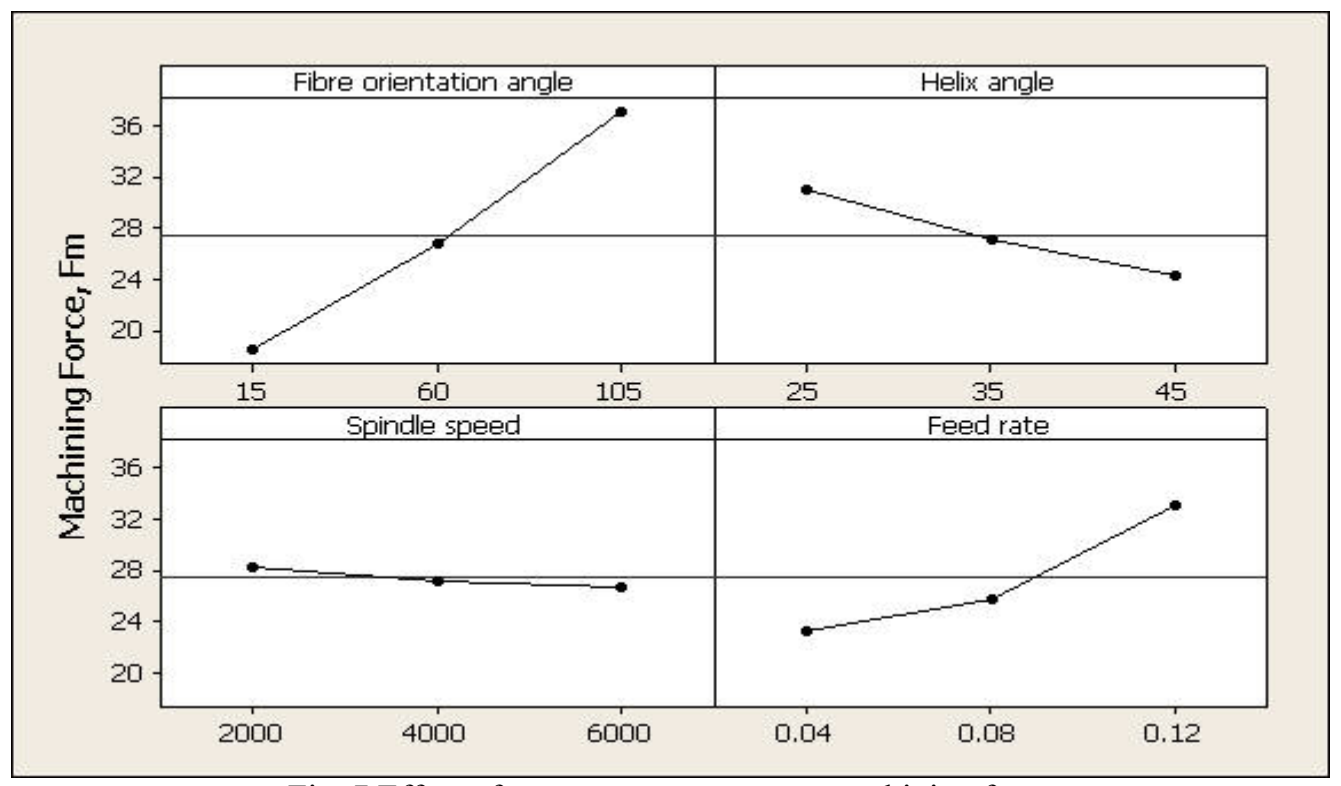

Fig. 7 Effect of process parameters on machining force 


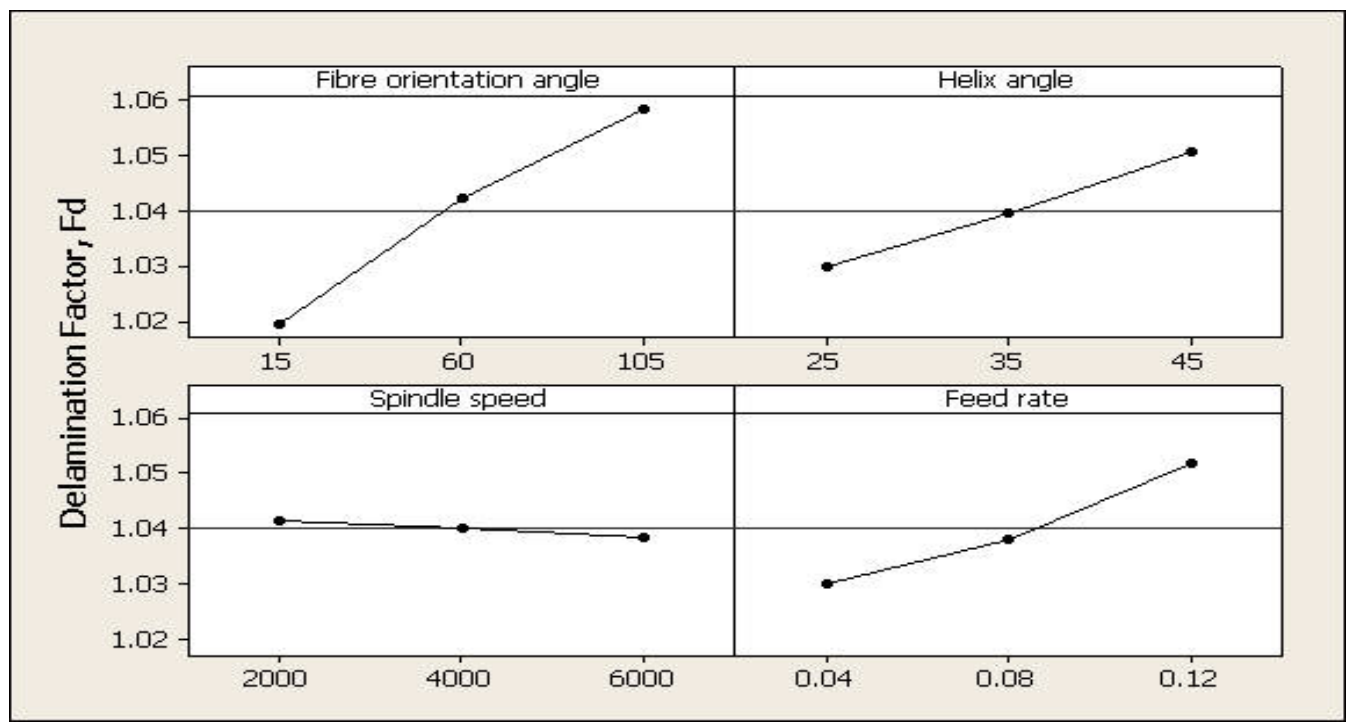

Fig. 8 Effect of process parameters on delamination factor
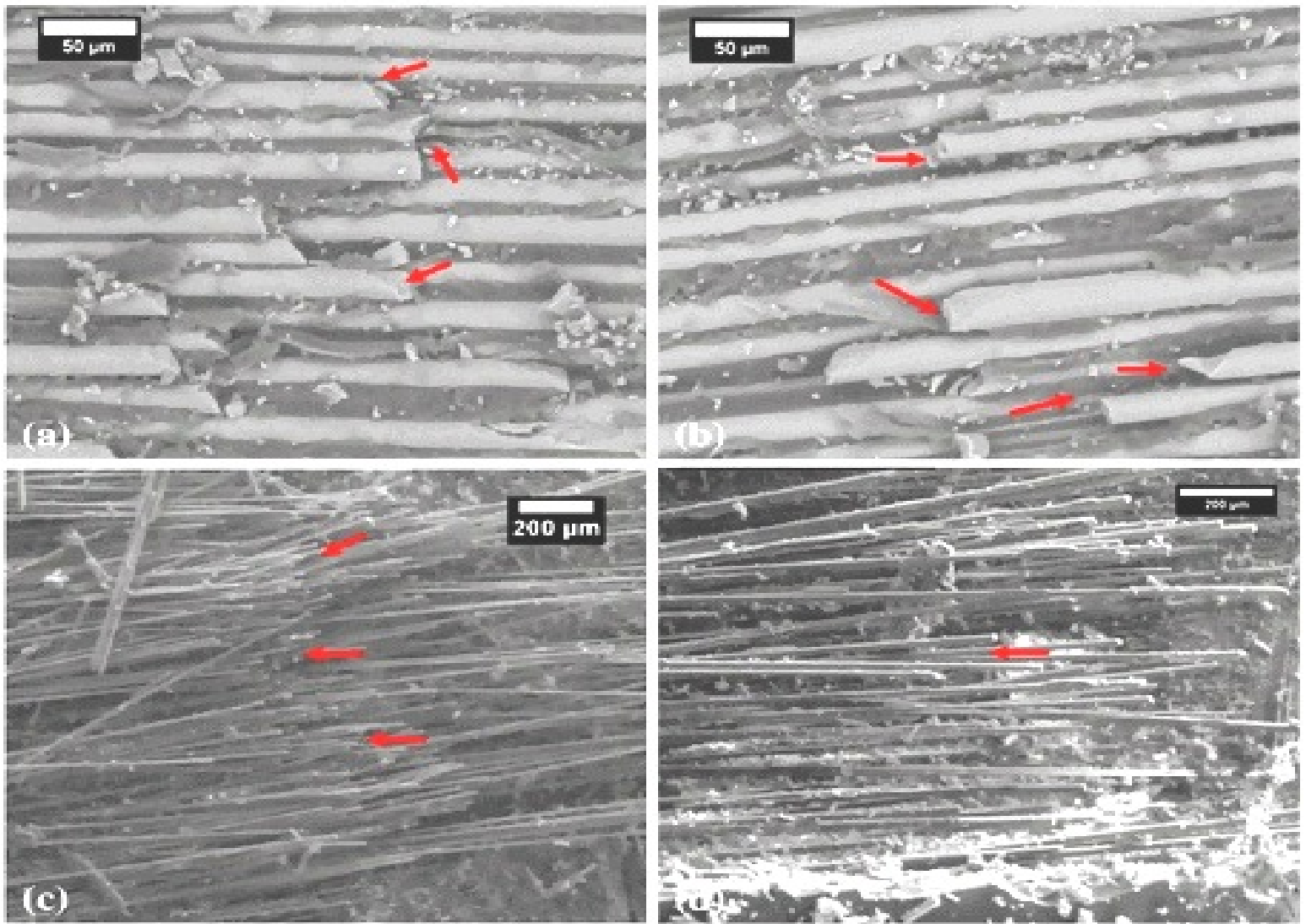

Fig. 10 Scanning Electron Micrographs of the machined surface.

Thus, in the scanning electron microscope (SEM) images of machined surfaces, Fig. 10a-b, it is apparent that sharp and brittle fractures of the fibres indicate these failure modes. On the other hand, Fig. 10c-d, displays evidence of fibres protrusion and pullout from machined surface due to fibre debonding or matrix failure and also shows the powdery chips along with fractured fibers. This is due to the high feed rate and large fibre orientation which creates large compressive strain within the matrix material. Fibre reinforcements are subjected to buckling and bending failures as the cutting progresses along the fibre direction.

\subsection{Effect of process parameters on composite desirability}

The effect of process parameters on composite desirability for GFRP composite plates are shown in Table 5 . The best values of various parameters for the combined objective (combined objective with $20 \%$ to delamination factor, $30 \%$ to machining force and 
$50 \%$ to surface roughness) of minimized delamination factor, machining force and surface roughness are identified as $\Phi 1 \Theta 1 \mathrm{~N} 2 \mathrm{fl}$ as shown in Fig. 9.

Table 5 Factor effects for composite desirability $\left(\mathrm{d}_{\mathrm{G}}\right)$ for GFRP composites

\begin{tabular}{ccccc}
\hline Levels & \multicolumn{5}{c}{ Factors } \\
\cline { 2 - 5 } & $\Phi$ & $\Theta$ & $\mathrm{N}$ & $\mathrm{F}$ \\
\hline 1 & 0.8548 & 0.6857 & 0.5889 & 0.7123 \\
2 & 0.6287 & 0.6261 & 0.6215 & 0.6387 \\
3 & 0.3412 & 0.5129 & 0.6143 & 0.4737 \\
\hline Optimum levels & $\Phi 1$ & $\Theta 1$ & $\mathrm{~N} 2$ & $\mathrm{f} 1$ \\
\hline
\end{tabular}

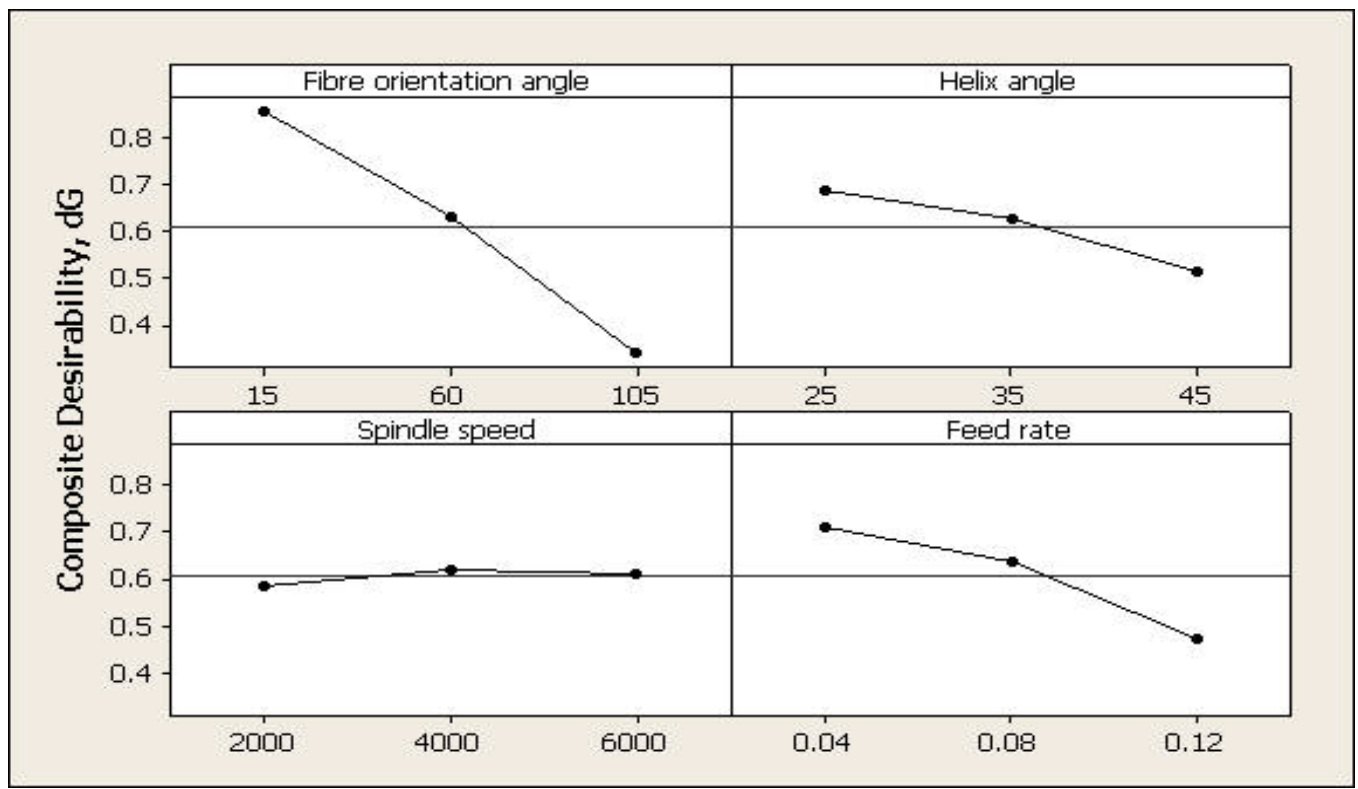

Fig.9 Effect of process parameters on composite desirability

\subsection{ANOVA for composite desirability}

The purpose of the statistical ANOVA is to investigate which design parameter significantly affects the surface roughness, machining force and delamination factor. Based on the ANOVA, the relative importance of the machining parameters with respect to surface roughness, machining force and delamination was investigated to determine more accurately the optimum combination of machining parameters. The analysis is carried out for the level of significance of 5\% (the level of confidence is $95 \%$ ). Table 6 shows the result of ANOVA analysis for the machining outputs of GFRP composite plates. From the Table 6, it is observed that the factor fibre orientation angle (Percentage contribution, $P=66.75 \%$ ) has statistical and physical significance on the composite desirability followed by feed rate $(P=15.05 \%)$, helix angle $(P=7.76 \%)$ and spindle speed $(P=0.30 \%)$ for GFRP composite plates.

Table 6 ANOVA for composite desirability $\left(\mathrm{d}_{\mathrm{G}}\right)$

\begin{tabular}{ccccccc}
\hline Factors & $\begin{array}{c}\text { Sum of } \\
\text { square }\end{array}$ & $\begin{array}{c}\text { Degree of } \\
\text { freedom }\end{array}$ & Mean square & F test & $\begin{array}{c}\text { Percentage } \\
\text { contribution }\end{array}$ & Rank \\
\hline$\Phi$ & 0.19258 & 2 & 0.5963 & 59.25 & 66.75 & 1 \\
$\Theta$ & 0.13859 & 2 & 0.0693 & 6.88 & 07.76 & 3 \\
$\mathrm{~N}$ & 0.00531 & 2 & 0.0026 & 0.26 & 00.30 & 4 \\
$\mathrm{f}$ & 0.26885 & 2 & 0.1344 & 13.36 & 15.05 & 2 \\
\hline Error & 0.18115 & 18 & 0.0101 & & 10.14 & \\
\hline Total & 1.78650 & 26 & 0.0687 & & 100 & \\
\hline
\end{tabular}




\subsection{Confirmation test}

The aim of the confirmation test is to validate conclusions drawn during the analysis phase. Once the optimum level of the process parameters is selected, the final step is to predict and verify the improvement of the performance characteristics using the optimum level of the process parameters. A validation experiment is conducted for the combined objective with the obtained best levels of parameters. The values for surface roughness, machining force and delamination factor from validation experiment for the GFRP plates are $0.81 \mu \mathrm{m}, 12.98 \mathrm{~N}$ and1.004 respectively. The percent improvement in surface roughness, machining force and delamination factor with the application of design of experiments is calculated from the validated result and the best values of responses from the Table 3 as:

The $\%$ improvement in surface roughness $=[(0.85-0.81) / 0.85] \times 100=4.71 \%$

The $\%$ improvement in machining force $=[(13.54-12.98) / 13.54] \times 100=4.14 \%$

The $\%$ improvement in delamination factor $=[(1.009-1.001) / 1.009] \times 100=0.694 \%$

\section{Conclusion}

Milling experiments were conducted based on Taguchi technique for GFRP composite material using solid carbide cutting tool. The experimentally collected data were subjected to desirability function analysis for optimisation of machining parameters. From this analysis, the following conclusions are drawn for Surface roughness, machining force and delamination.

- Desirability function in the Taguchi method for the optimisation of multi-response problems is a very useful tool for predicting surface roughness, machining force and delamination factor in milling GFRP composite plates.

- The implementation of DFA in DOE improves the surface roughness, machining force and delamination factor by $4.71 \%$, $4.14 \%$ and $0.694 \%$ respectively for the milling of GFRP plates.

- End mills with small helix angles develop the greatest machining force, lowest surface roughness and delamination factor.

- Surface roughness, machining force and delamination factor increases with increase in fibre orientation angle and feed rate, and decreases with increase in cutting speed.

- Fibre orientation angle $(P=66.75 \%)$ is the statistical and physical significant parameter followed by feed rate $(P=$ $15.05 \%)$, helix angle $(P=7.76 \%)$ and spindle speed $(\mathrm{P}=0.30 \%)$ for GFRP composite plates.

- Lower fibre orientation angle, lower helix angle, moderate spindle speed and lower feed rate ( 1 1 Ө1 N2 f1) are the ideal machining conditions for machining GFRP composite plates.

\section{Nomenclature}

$\begin{array}{ll}\text { GFRP } & \text { Glass fibre reinforced plastics } \\ \mathrm{N} & \text { Spindle speed in rpm } \\ \mathrm{f} & \text { Feed rate in } \mathrm{mm} / \mathrm{rev} \\ \Phi & \text { Fibre orientation angle in degree } \\ \Theta & \text { Helix angle in degree } \\ \mathrm{R}_{\mathrm{a}} & \text { Surface roughness value in } \mu \mathrm{m} \\ \mathrm{F}_{\mathrm{m}} & \text { Machining force in } \mathrm{N} \\ \mathrm{DOE} & \text { Design of experiments } \\ \mathrm{W}_{\mathrm{t}} & \text { Weightage } \\ \mathrm{TCN} & \text { Test condition number } \\ \mathrm{d}_{\mathrm{i}} & \text { Individual desirability for responses } \\ \mathrm{d}_{\mathrm{G}} & \text { Composite desirability } \\ \text { DFA } & \text { Desirability function analysis } \\ \text { ANOVA } & \text { Analysis of variance } \\ \mathrm{CNC} & \text { Computer numerical control }\end{array}$

\section{References}

Adeel Suhail, H., Ismail, N., Wong, S.V., Abdul Jalil, N.A. 2010. Optimisation of cutting parameters based on surface roughness and assistance of workpiece surface temperature in turning process. American Journal of Engineering and Applied Sciences, Vol. 3, pp. 102-108.

An, S.-O., Lee, E.-S., Noh, S.-L. 1997. A study on the cutting characteristics of glass fibre reinforced plastics with respect to tool materials and geometries. Journal of Materials Processing Technology Vol. 68, pp. 60-67. 
Asif Iqbal, A.K.M., Ahsan Ali Khan, 2010. Modelling and Analysis of MRR, EWR and Surface Roughness in EDM Milling through Response Surface Methodology. American journal of Engineering and Applied Sciences 3, 611-619 (2010)

Davim, J.P. 2001. A note on the determination of optimal cutting conditions for surface finish obtained in turning using design of experiments. Journal of Material Process Technology Vol. 116, pp. 305-308.

Davim, J.P., Mata, F. 2005. A new machinability index in turning fiber reinforced plastics. Journal of Materials Processing Technology Vol. 170, pp. 436-440.

Davim, J.P., Mata, F. 2007. New machinability study of glass fibre reinforced plastics using polycrystalline diamond and cemented carbide (K15) tools. Material Design, Vol. 28, pp. 1050-1054.

Davim, J.P., and Pedro Reis 2005. Damage and dimensional precision on milling carbon fibre-reinforced plastics using design experiments. Journal of Materials Processing Technology Vol. 160, pp. 160-167.

Davim, J.P., Reis, P., Conceicao, A.C.: 2004. A study on milling of glass fibre reinforced plastics manufactured by hand-lay up using statistical analysis (ANOVA). Composite Structures Vol. 64, pp. 493-500.

Derringer, G., Suich, R. 1980. Simultaneous optimization of several response variables. Journal of Quality Technology Vol. 12, pp. 214-219.

Erisken, E. 1999. Influence from production parameters on the surface roughness of a machine short fibre reinforced thermoplastic. International Journal of Machine Tools and Manufacture Vol. 39, pp. 1611-1618.

Ferreira, J. R., Coppini, N. L., Miranda, G. W. A. 1999. Machining optimization in carbon fibre reinforced composite materials. Journal of Material Processing Technology Vol. 92, pp. 135-140.

Godfrey, C., Onwubolu, Shivendra Kumar 2006. Response surface methodology-based approach to CNC drilling operations. Journal of Materials Processing Technology, Vol. 171, pp. 41-47

Hull, D., Clyne, T.W. 1996. An introduction to composite materials, Second Edition, Cambridge University Press.

Jamal Y. Sheikh-Ahmad, 2009. Machining of Polymer composites. Springer Science and Business Media LLC.

Julie Zhang, Z., Joseph Chenb, C., Daniel Kirby, E. 2007. Surface roughness optimization in an end-milling operation using the Taguchi design method. Journal of Materials Processing Technology, Vol. 184, pp. 233-239.

Kaneeda, T. 1989. CFRP cutting mechanism. In: Proceeding of the 16th North American Manufacturing Research Conference, pp. 216-221.

Koplev, A., Lystrup, A., Vorm, T. 1983. The cutting process, chips and cutting forces in machining CFRP. Composites Vol. 14, pp. $371-376$.

Mata, F., Davim, J.P. 2003. An investigation about the precision turning fibre reinforced plastics (FRP's) with diamond cutting tools using multiple analysis regression. Valencia: II Iberian Conference of Tribology, pp. 117-124.

Palanikumar, K., Karunamoorthy, L., Karthikeyan, R. 2006. Assessment of factors influencing surface roughness on the machining of glass fibre-reinforced polymer composites. Material Design, Vol. 27, pp. 862-871.

Praveen Raj, P., Elaya Perumal, A. 2010. Taguchi Analysis of surface roughness and delamination associated with various cemented carbide K10 end mills in milling of GFRP. Journal of Engineering Science and Technology Review, 3, pp. 58-64.

Puw, H.Y., Hocheng, H. 1995. Anisotropic chip formation models of cutting of FRP. In: ASME Symposium on Material Removal and Surface Modification Issues in Machining Processes, New York.

Ramkumar, J., Aravindan, S., Malhotra, S.K., Krishnamoorthy, R. 2004. An enhancement of the machining performance of GFRP by oscillatory assisted drilling. International Journal of Advanced Manufacturing Technology, Vol. 23, pp. $240-244$.

Ramulu, M., Arola, D., Colligan, K. 1994. Preliminary investigation of effects on the surface integrity of fibre reinforced plastics. In: Engineering systems design and analysis 2, ASME, Vol. 64, pp. 93-101

Ramulu, M., Wern, C.W., Garbini, J.L. 1993. Effect of the direction on surface roughness measurements of machined graphite/epoxy composite. Composites Manufacturing, Vol. 4, pp. 39-51.

Santhanakrishman, G., Krishnamurthy, R., Malhota, S.K. 1988. Machinability characteristics of fibre reinforced plastics composites. Journal of Mechanical Working Technology, Vol. 17, pp. 195-204.

Singh, I., Bhatnagar, N. 2006. Drilling of uni-directional glass fibre reinforced plastic (UD-GFRP) composite laminates. International Journal of Advanced Manufacturing Technology, Vol. 27, pp. 870-876

Sreejith, P. S., Krishnamurthy, R., Malhota, S.K., Narayanasamy, K. 2000. Evaluation of PCD tool performance during machining of carbon/Phenolics ablative composites. Journal of Material Processing Technology, Vol. 104, pp. 53-58

Suleyman Neseli, Suleyman Yaldizand, and Erol Turkes 2011. Optimisation of tool geometry parameters for turning operations based on the response surface methodology. Measurement, Vol. 44, pp. 580-587.

Wang, X.M. and Zhang, L.C. 2003. An experimental investigation into the orthogonal cutting of unidirectional fibre reinforced plastics. International Journal of Machine Tools Manufacturing, Vol. 43, pp. 1015-1022.

\section{Biographical notes}

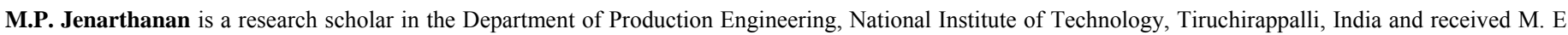

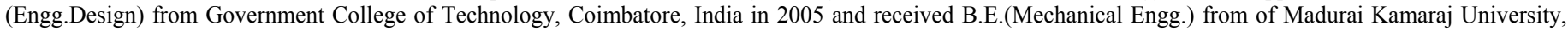

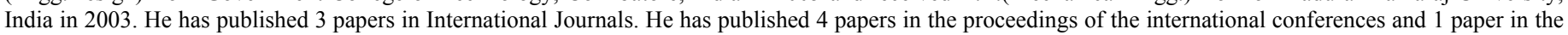
proceedings of national conference. His research interests include modelling and analysis of machinability of FRP composites. 
Dr. R. Jeyapaul is an Associate Professor in the Department of Production Engineering, National Institute of Technology, Tiruchirappalli, India. He has more than 15 years of experience in teaching and research. His current area of research includes Design of Experiments, Taguchi Methodology. He has published more than thirty papers in referred international journals. He has also presented more than thirty research articles in national and international conferences.

Received January 2013

Accepted April 2013

Final acceptance in revised form May 2013 